Special Issue of the 8th International Advances in Applied Physics and Materials Science Congress (APMAS 2018)

\title{
Electrochemical Characteristics of Aluminum Alloys in Sea Water for Marine Environment
}

\author{
Y.J. YANG ${ }^{a}$ AND S.J. KIM ${ }^{b, *}$ \\ ${ }^{a}$ Ajou University, Department of Energy Systems Research, Suwon, Korea \\ ${ }^{b}$ Mokpo National Maritime University, Division of Marine Engineering, Mokpo, Korea
}

\begin{abstract}
To evaluate the corrosion resistance of the 5xxx series (5052-O and 5083-H321) Al-Mg alloys and the 6xxx series (6061-T6) Al-Mg-Si alloys used in marine environments, various electrochemical experiments were conducted and the surface damages were analyzed. In the results of cathodic polarization experiments, 6061-T6 was judged to have the best anticorrosive properties because of the lowest required current density in the cathodic protection potential section and of uniform calcareous deposit formed on the surface. In addition, in the results of cyclic polarization experiments, the pitting resistance of 6061-T6 was shown to be the highest During the anodic polarization experiments 6061-T6 presented the least surface damage. Through electrochemical experiments, 6061-T6 was selected as an aluminum alloy material with excellent corrosion resistance in marine environments.
\end{abstract}

DOI: 10.12693/APhysPolA.135.1005

PACS/topics: electrochemical experiment, aluminum alloy, corrosion, marine environment

\section{Introduction}

Aluminum alloys have been in the limelight recently in the whole world as ship hull materials because they have higher corrosion resistance compared to other metals, can be recycled as their melting points are low, and have excellent machinability, specific strength, and fatigue properties [1]. In particular, the tendency for existing small ships, fishing boats, and leisure ships made of fiber reinforced plastics (FRP) to be replaced by aluminum ship has been prominent because FRP ships have shortcomings such as discharging chemical substances in the drying process, being vulnerable to external impacts and fire, and having shown cases of collision accidents due to low radar wave reflection intensity as well as requiring considerable ship scrapping costs [2]. On the contrary, aluminum ships well endure external shocks because they are very strong and they are safe in fire because they are flame retardant. In addition, their hull shapes can be freely made according to designs because they are made without using any mold and their fuel efficiency can be enhanced because aluminum alloys are lighter than FRP materials. However, since aluminum alloys show big differences in mechanical strength and corrosion resistance depending on alloy components and heat treatment conditions, attention should be paid to appropriate material selection according to use environments. Therefore, to briefly review recent study trends, Rosliza et al. [3] conducted diverse electrochemical experiments with AA6061 aluminum alloy at room temperature using tropical seawater. As a result, they proved that sodium benzoate is an effective corrosion inhibitor for AA6061 in sea water. Guan et al. [4] investigated the effects of sulfate-reducing

*corresponding author; e-mail: ksj@mmu.ac.kr bacteria (SRB) living in seawater and sea mud environments on the corrosion of 5052 aluminum alloy. According to the results, the corrosion of 5052 aluminum alloy was accelerated by SRB because 5052 aluminum alloy augmented the SRB metabolic activity and SRB further promoted the anodic dissolution reactions of 5052 aluminum alloy. Meanwhile, Zhang et al. [5] comprehensively investigated the intergranular corrosion and intergranular stress corrosion of diverse $5 \mathrm{xxx}$ series aluminum alloys due to sensitization following the precipitation of $\beta$-phase $\mathrm{Mg}_{2} \mathrm{Al}_{3}$. In particular, with regard to the sensitization of 5xxx series aluminum alloys, the researchers presented matters to be attended to in relation to the bulk composition, heat treatment, and microstructure of the aluminum alloys.

In the present study, 5000 series $\mathrm{Al}-\mathrm{Mg}$ alloys and 6000 series $\mathrm{Al}-\mathrm{Mg}$-Si alloys that are mainly used in marine environments were selected and the corrosion resistance of these alloys was evaluated with a view to selecting the aluminum alloy material the most suitable as ship hull materials. Various electrochemical polarization experiments were conducted for evaluation of the corrosion resistance and the tendency of the surface damage was studied.

\section{Experimental procedure}

In the present study, three materials: 5052-O, 5083H321, and 6061-T6 were selected and their compositions are shown in Table I. For electrochemical experiments, polarization experiments were conducted using US/PCI4/750 from GAMRY Instrument Co. The specimens were cut to $2 \mathrm{~cm} \times 2 \mathrm{~cm}$ size and were ground by stages to sandpaper $\# 2000$. Thereafter, the specimens were ultrasonic cleaned in distilled water for $1 \mathrm{~min}$ and degreased with acetone. During the electrochemical experiments, an effective area of $1 \mathrm{~cm}^{2}$ of all specimens was identically exposed and a platinum $(\mathrm{Pt})$ elec- 
trode was used as a counter electrode and a $\mathrm{Ag} / \mathrm{AgCl}$ electrode as a reference electrode. Natural seawater was used as a solution and the major components and basic characteristics of this solution are shown in Table II. As electrochemical polarization experiments for evaluation of corrosion resistance, anodic polarization experiments, cathodic polarization experiments, and cyclic polarization experiments were conducted. In all the polarization experiments, the specimens were stabilized by immersion in the seawater solution for 3,600 s before experiment and were polarized based on the open circuit potential (OCP). In the anodic polarization experiments, the specimens were polarized from OCP up to $+2 \mathrm{~V}$ at a scanning rate of $1 \mathrm{mV} / \mathrm{s}$ and in the cathodic polarization experiments, the specimens were polarized down to $-2 \mathrm{~V}$ under the same condition. After the anodic polarization and cathodic polarization experiments, the surfaces of the specimens were analyzed using a scanning electron microscope (SEM) and a 3D optical microscope (Motic, PSM-100, Isolution). In the cyclic polarization experiments, potentials corresponding to the current densities ranging from $-0.2 \mathrm{~V}$ to potential corresponding to a current density of $1 \mathrm{~A} / \mathrm{cm}^{2}$ on the basis of the OCP were applied at a scanning rate of $1.67 \mathrm{mV} / \mathrm{s}$ (forward direction) and thereafter, the potential was reversed and applied so that $-0.2 \mathrm{~V}$ was reached (reverse direction) when the experiments were ended.

TABLE I

Chemical composition of aluminum alloys.

\begin{tabular}{c|c|c|c|c|c|c}
\hline \hline & \multicolumn{6}{|c}{ Element [wt\%] } \\
\cline { 2 - 7 } Material & $\mathrm{Mg}$ & $\mathrm{Si}$ & $\mathrm{Fe}$ & $\mathrm{Mn}$ & $\mathrm{Cr}$ & $\mathrm{Cu}$ \\
\hline $5052-\mathrm{O}$ & 2.31 & 0.0005 & 0.284 & 0.197 & 0.177 & 0.0005 \\
$5083-\mathrm{H} 321$ & 4.48 & 0.0005 & 0.358 & 0.542 & 0.0652 & 0.0133 \\
$6061-\mathrm{T} 6$ & 0.8252 & 0.3104 & 0.441 & 0.0069 & 0.1809 & 0.2086
\end{tabular}

TABLE II

Chemical composition and properties of seawater.

\begin{tabular}{|c|c|c|c|c|c|}
\hline \multicolumn{6}{|c|}{ Main component [mg/L] } \\
\hline $\mathrm{SO}_{4}^{2-}$ & $\mathrm{Cl}$ & $\mathrm{Na}^{+}$ & $\mathrm{K}^{+}$ & $\mathrm{Mg}^{2+}$ & $\mathrm{Ca}^{2+}$ \\
\hline 2.605 & 17.388 & 10.414 & 361 & 1.215 & 402 \\
\hline & \multicolumn{2}{|c|}{ electric conductivity } & & \multicolumn{2}{|c|}{$\begin{array}{c}10.2 \mathrm{mS} / \mathrm{cm} \\
49.7 \mathrm{mg} / \mathrm{L}\end{array}$} \\
\hline
\end{tabular}

\section{Results and discussion}

Figure 1 is a graph that displays the cathodic polarization curves according to the grades of aluminum alloys in natural seawater. In the case of all specimens, the current density generally increased as the potential dropped from the OCP and similar tendencies to undergo three stages of cathodic reactions according to changes in the current density were observed. First, after the initial

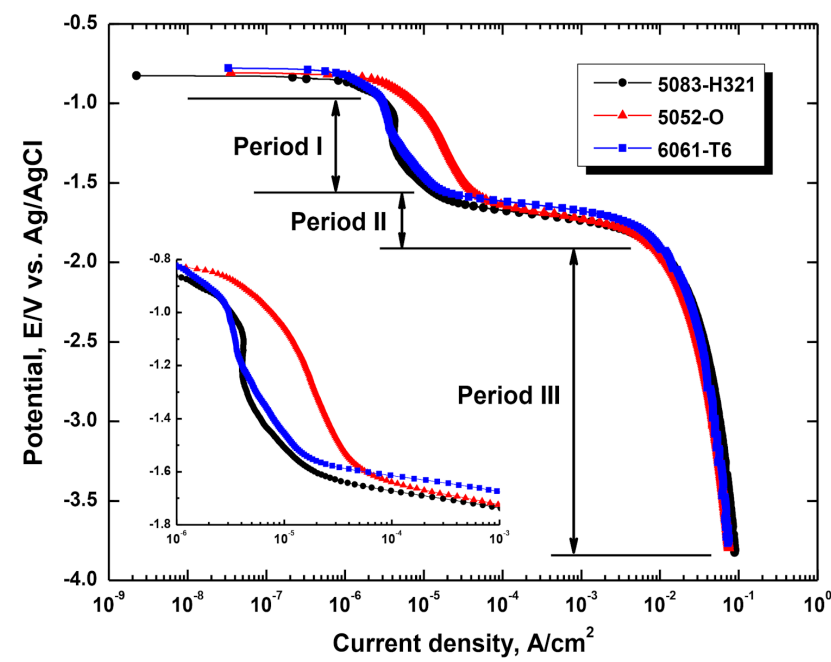

Fig. 1. Cathodic polarization curves of aluminum alloys in sea water.

activation polarization, a concentration polarization section (Period I) resulted from the reduction reactions of dissolved oxygen $\left(\mathrm{O}_{2}+2 \mathrm{H}_{2} \mathrm{O}+4 e^{-} \rightarrow 4 \mathrm{OH}^{-}\right)$appeared in the section of around $-0.95 \mathrm{~V} \sim-1.6 \mathrm{~V}[6]$. When the levels of current density in the concentration polarization section were compared with each other, 5052-O presented the relatively largest value while 6061-T6 and 5083-H321 showed similar values. The levels of current density in concentration polarization sections according to cathodic polarization are related to the degree of $\mathrm{OH}^{-}$forming reactions by the reduction reaction of dissolved oxygen on the surface, which are major reactions. In addition, $\mathrm{OH}^{-}$reacts with $\mathrm{Mg}^{2+}$ existing in seawater to promote the precipitation of $\mathrm{Mg}(\mathrm{OH})_{2}$, which is a constituent of calcareous deposit [7]. Therefore, 5052-O that showed the highest current density is expected to form the thickest film when applied with cathodic protection. These films play the role of physical barriers that suppress the migration of electrons and dissolved oxygen [8]. In the past, films were formed in advance before anodic protection to reduce the effective protection area with a view to reducing the required current density [7]. Recently, anticorrosion techniques to adjust supply currents so that the calcareous deposit is evenly precipitated on the surface have been studied $[9,10]$. Thereafter, a turning point at which the current density rapidly increased as the applied potential decreased was observed. A turning point appears at the point where the hydrogen bubble generation reactions become dominant as the dissolved oxygen has been depleted. When the applied potential dropped further to around $-1.6 \sim-1.9 \mathrm{~V}$, activation polarization (Period II), which is the second major cathodic reaction, appeared. In this activation polarization section, the following electrochemical reactions occurss on the surface of specimen:

$$
\begin{aligned}
& \mathrm{H}^{+}+e^{-} \longrightarrow \mathrm{H}_{\mathrm{ads}} . \\
& \mathrm{H}_{\mathrm{ads}}+\mathrm{H}_{\mathrm{ads}} \longrightarrow \mathrm{H}_{2} .
\end{aligned}
$$


In Eq. (1) $\mathrm{H}^{+}$reacts with electrons to form absorbed hydrogen atoms, in Eq. (2) the absorbed atoms are combined with each other to become hydrogen molecules. Thereafter, when the hydrogen molecules are sufficiently formed, they are gathered so that hydrogen bubbles are formed [6-9]. Meanwhile, when the applied potential has been dropped further so that the hydrogen reactions occurring of the surface of specimens led to the threshold current density, the water is directly reduced and hydrogen bubbles are formed:

$$
2 \mathrm{H}_{2} \mathrm{O}+2 e^{-} \longrightarrow 2 \mathrm{OH}^{-}+\mathrm{H}_{2} \uparrow \text {. }
$$

(Period III). In this section, all specimens showed quite similar tendencies [6-9]. In this case, attention should be paid to the hydrogen (ion or atom) generated in the areas adjacent to the surface of specimens by the above three different reactions because the hydrogen may penetrate into the material for have negative effects. Excessive cathodic protection may generate strong electromagnetic attractive force for hydrogen ions with positive charges so that the hydrogen ions can easily diffuse to metal surfaces or the inside of metal crystals. Therefore, when hydrogen is gathered inside the metal crystals so that hydrogen bubbles are formed, the crystals are damaged and internal void and surface blister phenomena become to occur [6]. In this case, the mechanical strength and ductility of the metal may decline leading to brittle cracks.
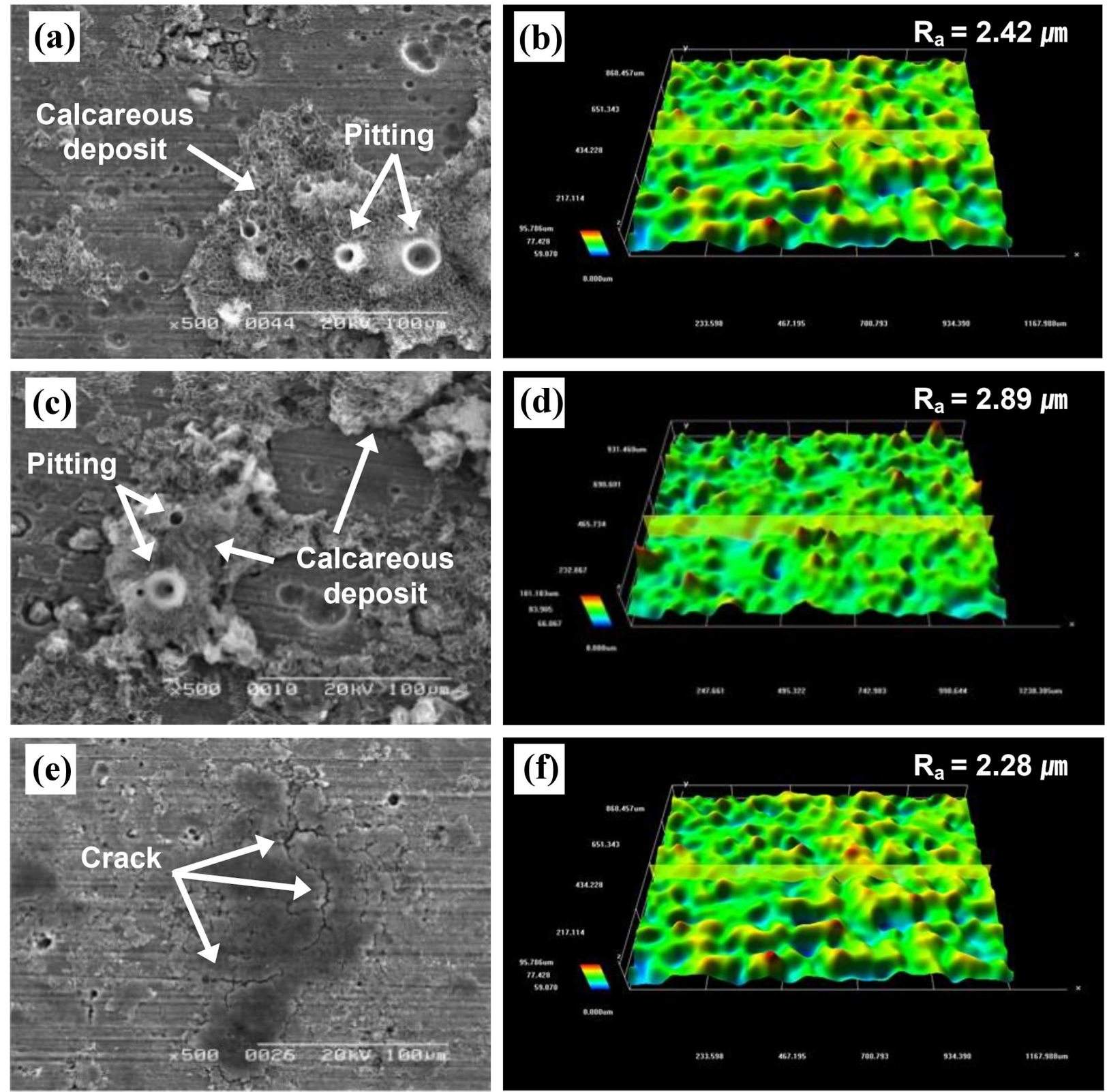

Fig. 2. SEM and 3D analysis of aluminum alloys surface after cathodic polarization experiment in sea water; (a)-(b) 5083-H321, (c)-(d) 5052-O, and (e)-(f) 6061-T6. 
Figure 2 presents the surface of aluminum alloys after cathodic polarization experiments in natural seawater observed using a SEM and a 3D microscope. First, in Fig. 2 a and c, pitting corrosion was observed on the surface of the specimen along with calcareous deposit and in Fig. 2e, cracks were observed on the calcareous deposit. This can be attributed to the fact that parts of the films were damaged due to the formation of the calcareous deposit and fast hydrogen generation occurring simultaneously in the activation polarization section. The excessive current densities supplied to the damaged areas leads to rapid increases in the generation of hydrogen bubbles so that surface damage developed [9]. The calcareous deposit formed on the surface consists mainly of $\mathrm{Mg}(\mathrm{OH})_{2}$ and $\mathrm{CaCO}_{3}$ and is precipitated through the following reactions. First, $\mathrm{Mg}(\mathrm{OH})_{2}$ is generated through the reactions between the $\mathrm{OH}^{-}$ions generated when dissolved oxygen or water is reduced and the $\mathrm{Mg}^{2+}$ ions dissolved in the seawater

$$
\mathrm{Mg}^{2+}+2 \mathrm{OH}^{-} \longrightarrow \mathrm{Mg}(\mathrm{OH})_{2}(\mathrm{~s}) \text {. }
$$

Next $\mathrm{CaCO}_{3}$ is precipitated with carbon dioxide dissolved in seawater

$$
\mathrm{CO}_{2}+\mathrm{H}_{2} \mathrm{O} \longrightarrow \mathrm{H}_{2} \mathrm{CO}_{3},
$$

ionized

$$
\mathrm{H}_{2} \mathrm{CO}_{3} \Longleftrightarrow 2 \mathrm{H}+\mathrm{CO}_{3}^{2-} \longrightarrow \mathrm{H}^{+}+\mathrm{HCO}_{3-},
$$

and the ions react with calcium ions

$$
\mathrm{Ca}^{2+}+\mathrm{CO}_{3}^{2-} \longrightarrow \mathrm{CaCO}_{3} \text {. }
$$

Therefore, calcareous deposit composed of calcium compounds forms the films on the cathodic surface [7-10].

Through 3D analyses, surface roughness (average roughness, $R_{a}$ ) was measured to be the largest in 5052-O followed by 5083-H321 and 6061-T6 in order of precedence. This is because the general cathode current density of 5052-O was formed to be the largest and the calcareous deposit of 5052-O was formed locally. On the contrary, the calcareous deposit on 6061-T6 was formed more evenly on the entire surface compared to 5083-H321 so that the surface roughness was measured to be relatively smaller.

Consequently, if cathodic protection should be applied to aluminum alloys, the state of formation of calcareous deposit films and appropriate protection potentials should be comprehensively considered. In the present study, since the protection potential sections (Period I) of the three aluminum alloys were formed almost identically, 6061-T6, in which relatively low cathode current densities were formed and calcareous deposit was evenly formed on the surface in the protection potential section, can be judged as an appropriate material when cathodic protection is applied.

Anodic polarization experiments were conducted to understand the tendency toward surface damage of aluminum alloys and anodic polarization curves of aluminum alloys in natural seawater are shown in Fig. 3. All specimens showed general increases in the current density as their potentials rose from OCP. Depending on the

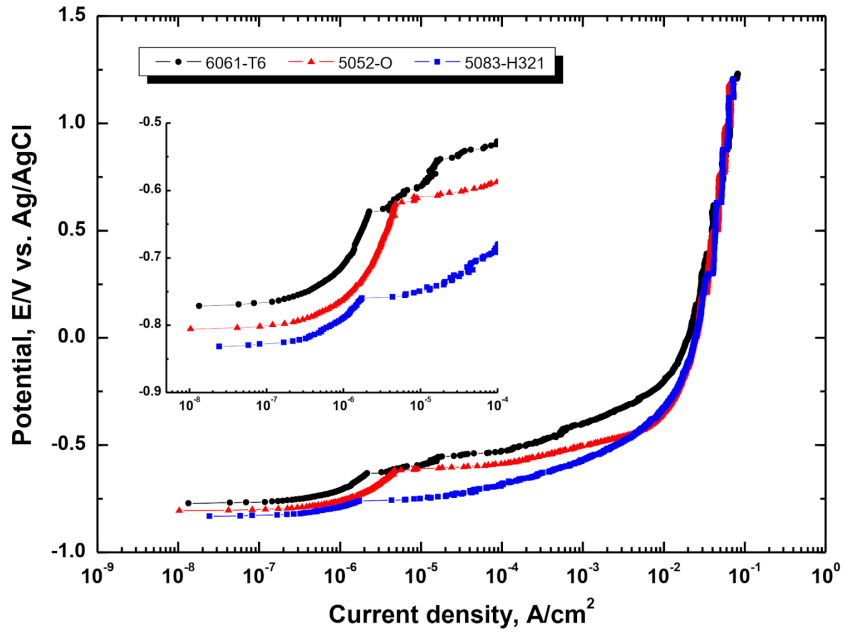

Fig. 3. Anodic polarization curve of aluminum alloys in sea water.

kind of specimens, points where the current density began to increase rapidly were observed in the range of $-0.8 \sim-0.6 \mathrm{~V}$. The potential in this case is called pitting potential $\left(E_{p i t}\right)$. The more the potential exceeds $E_{\text {pit }}$, the better is the pitting resistance in general [6]. The pitting damages occurring at the $E_{p i t}$ level as such occurs first in relatively vulnerable areas of oxide films and grows due to active dissolution reactions [11, 12]. Meanwhile, when the current densities of individual specimens after $E_{\text {pit }}$ following changes in the applied potential were compared with each other, 6061-T6 showed the smallest value followed by $5052-\mathrm{O}$ and $5083-\mathrm{H} 321$ in order of precedence. Therefore, in the anodic polarization potential section implemented in the present study, the corrosion resistance of 6061-T6 that showed relatively low current densities is considered to be the most excellent.

Figure 4 shows the results of observation of the damaged surfaces of aluminum alloys after anodic polarization experiments in natural seawater using SEM. First, in Fig. 4a, c, and e, 5083-H321 and 5052-O specimens unveil large surface damages in the entire exterior, 6061T6 shows only small local surface damages. As shown in Fig. 4b, d, and $\mathrm{f}$, the damaged areas of aluminum alloys were magnified and analyzed. As the results, the crystal structure shapes generally observed in aluminum alloys during dissolution reactions by anodic polarization were identified. The shapes and sizes of the crystals differ with specimens. These crystal structures appear because differences in potential are generated by the differences in surface energy between crystal faces so that active dissolution reactions are promoted along certain crystal faces $[13,14]$. The pitting potential of single crystal FCC aluminum is known to decrease in order of $\{001\}>$ $\{011\}>\{111\}$ and the active dissolution rate is known to decrease in order of $\{001\}<\{011\}<\{111\}$ [13]. According to the studies of other researchers, who measured the chlorine concentration in oxide films on aluminum single crystals in a solution containing chlorine ions, 

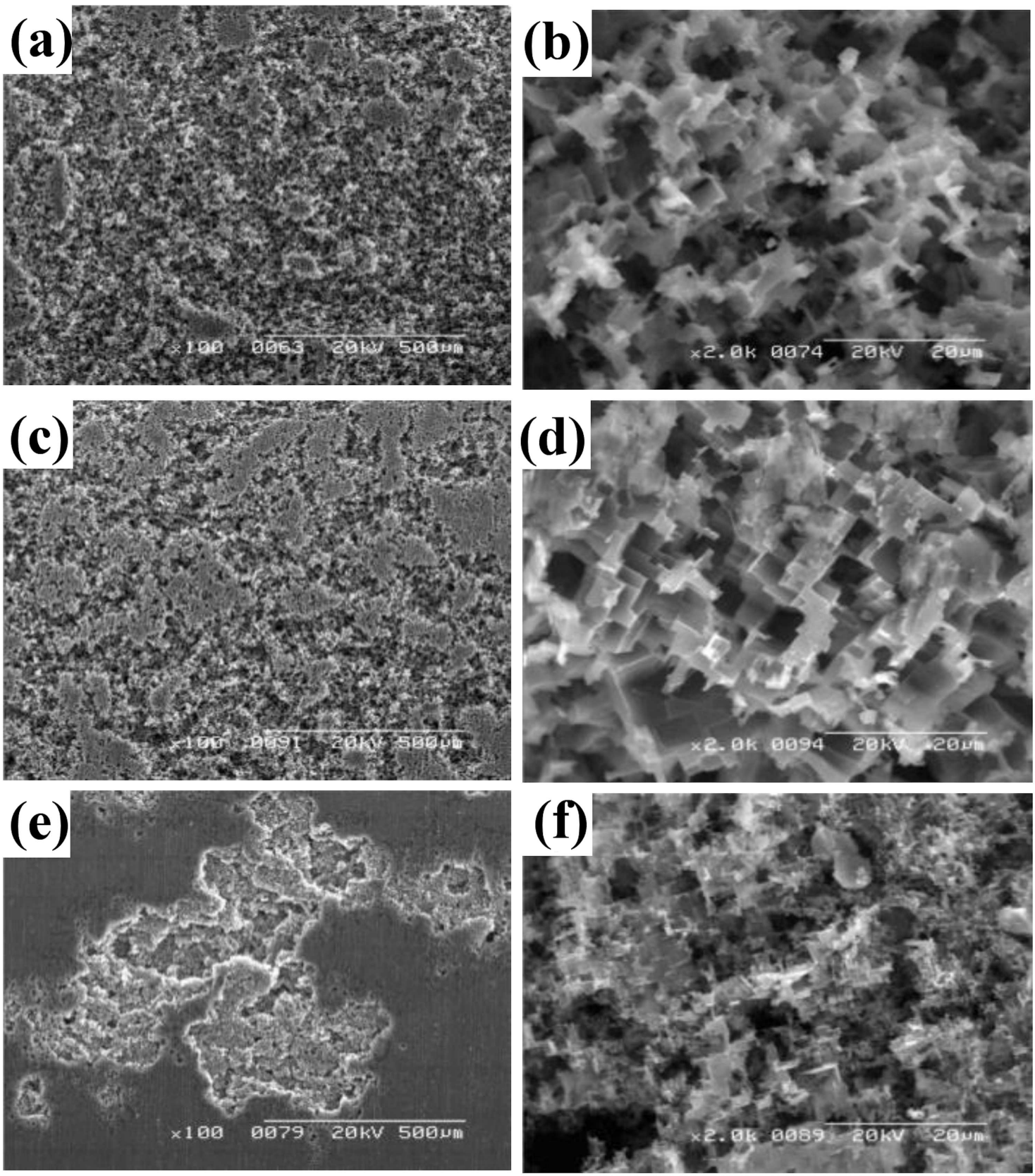

Fig. 4. Surface morphologies of aluminum alloys after anodic polarization experiment in sea water; (a), (b) 5083-H321, (c), (d) 5052-O, and (e), (f) 6061-T6.

while applying anodic polarization measure potentials in order to crystal face, chlorine ion absorption and migration of face $\{110\}$ increased around the pitting potential so that face $\{110\}$ showed lower potentials compared to face $\{111\}[14]$. As such, crystal shapes are considered to appear because certain faces of crystals are dissolved faster. In addition, the sizes and shapes of crystal structures are known to vary with the elements included in the alloy and heat treatment conditions [14]. In Fig. $4 \mathrm{~b}$ and $\mathrm{d}$, in the case of 5083-H321 and 5052-O, crystal structures were shown relatively clearly because of active dissolution reactions and the sizes were observed to be large. On the contrary, in Fig. 4f, the shapes of the crystal structures of 6061-T6 were shown to be irregular and the sizes were observed to be small. These results are consistent with the results shown in Fig. 3 where the anode current densities of 6061-T6 according to changes in the potential were shown to be small.

Cyclic polarization experiments were conducted to evaluate pitting damages according to aluminum alloys in natural seawater and the resultant curves are shown in Fig. 5. In all specimens, during forward direction scanning, sections of around $-0.8 \sim-0.45 \mathrm{~V}$ where the current density increase rates were reduced by natural oxide 


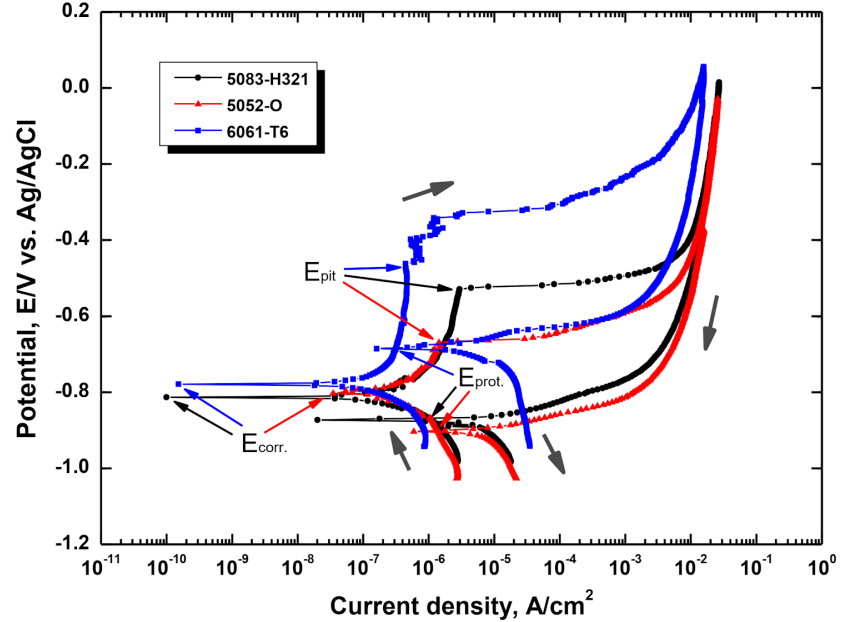

Fig. 5. Cyclic polarization curve of aluminum alloys in sea water.

films were observed and the current density rapidly increased as the applied potential increased because of the occurrence of pitting. The potential in this case is called pitting potential $\left(E_{p i t}\right)[6,15,16]$. Thereafter, as the direction of scanning was reversed and the applied potential decreased, the current density decreased. However, a hysteresis phenomenon to show higher current densities compared to forward direction curves was observed and an intersecting point with forward direction scanning appeared. The potential at this intersecting point is called protection potential $\left(E_{\text {prot }}\right)[6,15,16]$. When the applied potential decreased in reverse direction scanning and has a value between the protection potential and pitting potential $\left(E_{\text {pit }}>E>E_{\text {prot }}\right)$, no pitting occurs newly but the pittings that were formed during the forward direction scanning grow. Therefore, it can be said that the smaller is the potential difference as such, the larger is the resistance to pitting growth. However, in the case 6061-T6 the fluctuations of the current density appeared at potentials in a range of about $-0.45 \sim-0.34 \mathrm{~V}$ and a section of rapid increases in the current density was observed thereafter. This is considered attributable to the fact that the processes of the formation of fine pittings and repassivation were repeated and the section of rapid increases in current density appeared at a point of around $-0.34 \mathrm{~V}$ where repassivation cannot occur any longer as the applied potential increased. Consequently, as shown in Table III, when the differences between the protection potential and the pitting potential $\left(E_{p i t}-E_{\text {prot }}\right)$ of individual specimens were compared, the difference of 6061T6 was the smallest followed by 5052-O and 5083-H321 in order of precedence. Therefore the corrosion resistance of $6061-\mathrm{T} 6$ is judged to be the best. Since the pitting resistance of 6061-T6 is superior, during anodic polarization experiments, pittings occurred at the highest potential and the lowest anode current density was formed so that relatively small surface damages were occurred in 6061-T6.
TABLE III

Results of cyclic polarization experiments analysis of aluminum alloys in sea water.

\begin{tabular}{c|c|c|c}
\hline \hline & $5083-\mathrm{H} 321$ & $5052-\mathrm{O}$ & $6061-\mathrm{T} 6$ \\
\hline$E_{\text {corr }}[\mathrm{V}]$ & -0.812 & -0.802 & -0.779 \\
$E_{p i t}[\mathrm{~V}]$ & -0.528 & -0.668 & -0.459 \\
$E_{p p}[\mathrm{~V}]$ & -0.868 & -0.899 & -0.683 \\
$E_{p i t-p p}[\mathrm{~V}]$ & 0.340 & 0.231 & 0.224
\end{tabular}

\section{Conclusion}

To compare the electrochemical characteristics of aluminum alloys used in marine environments, their corrosion resistance were compared with each other through various experiments.

1. Based on the results of cathodic polarization experiments, 6061-T6 is judged to exert the most effective protection performance because the calcareous deposit was evenly formed on the overall surface of 6061-T6 and 6061-T6 showed relatively lower current densities in the concentration polarization section.

2. During anodic polarization experiments, the anode current densities of 6061-T6 were formed to be the lowest in general. Therefore, whereas corrosion damages occurred on the entire surfaces of 5083H321 and 5052-O, only local small surface damages occurred in the case of 6061-T6.

3. Through cyclic polarization experiments, the pitting resistance of 6061-T6 was shown to be the most excellent. Therefore, the anode current density and surface damage of 6061-T6 were shown to be the lowest.

4. In the present study, when overall electrochemical characteristics were considered, 6061-T6 was judged to be the most suitable as an aluminum alloy material for marine environments.

\section{Acknowledgments}

This research was a part of the project titled 'Next generation Korea-model fishing vessel development \& testbed application', funded by the Ministry of Oceans and Fisheries, Korea. This research was a part of the project titled 'The project for $100 \mathrm{ft}$ mega yacht construction including in R\&D for main technologies', funded by the Ministry of Oceans and Fisheries, Korea.

\section{References}

[1] C. Vargel, Corrosion of Aluminium, 1st ed., Elsevier, Amsterdam 2004.

[2] S.J. Kim, J.I. Kim, J.S. Kim, J. Kor. Inst. Surf. Eng. 40, 262 (2007). 
[3] R. Rosliza, H.B. Senin, W.W. Nik, AJSTD 25, 251 (2017).

[4] F. Guan, X. Zhai, J. Duan, J. Zhang, K. Li, B. Hou, Surf. Coat. Technol. 316, 171 (2017).

[5] R. Zhang, S.P. Knight, R.L. Holtz, R. Goswami, C.H.J. Davies, N. Birbilis, Corrosion 72, 144 (2015).

[6] D.A. Jones, Principles and Prevention of Corrosion, 2nd ed., Prentice-Hall, London 1996.

[7] W.H. Hartt, C.H. Culberson, S.W. Smith, Corrosion 40, 609 (1984)

[8] S.L. Wolfson, W.H. Hartt, Corrosion 37, 70 (1981).

[9] J.M. Park, J.W. Kang, I.H. Choi, S.H. Lee, K.M. Moon, M.H. Lee, J. Kor. Inst. Surf. Eng. 49, 66 (2016).
[10] C.J. Li, M. Du, RSC Adv. 7, 28819 (2017).

[11] E. MaCafferty, Corros. Sci. 45, 1421 (2003).

[12] R.T. Foley, Corrosion 42, 277 (1986).

[13] M. Yasuda, F. Weinberg, D. Tromans, J. Electrochem. Soc. 137, 3708 (1990).

[14] V.S. Sinyavskii, Prot. Met. 37, 469 (2001).

[15] M. Trueba, S.P. Trasatti, Mater. Chem. Phys. 121, 523 (2010).

[16] Z. Ahmad, A. Ul-Hamid, B.J. Abdul-Aleem, Corros. Sci. 43, 1227 (2001). 